\title{
Malignant soft tissue sarcoma of the shoulder treated by surface mould brachytherapy boost in an adjuvant setting
}

\author{
Ashutosh Mukherji, MD', Mourougan Sinnatamby, PhD² \\ 'Department of Radiotherapy, ${ }^{2}$ Department of Medical Physics, Regional Cancer Centre, JPMER, Puducherry, India
}

\begin{abstract}
Purpose: Soft tissue sarcomas of the extremities account for half of all soft tissue sarcomas. Radiotherapy and surgery have been the standard modalities in the treatment of this type of cancer. Brachytherapy can be used as the sole therapy, if the target volume is localized and easily accessible. This work reports three cases of shoulder soft tissue sarcomas with positive deep resected margins, treated with a combination of external beam radiotherapy and surface mould brachytherapy boost technique.

Material and methods: Between January and June 2014, three patients received brachytherapy with sites close to the shoulder, and post-surgery involved deep resected margins. Each mould was made on a base of thermoplastic, over which dental wax was coated and catheters implanted. The target volume was defined as the tissue covering the tumor bed with lateral margins of $2-2.5 \mathrm{~cm}$ and depth of $1-1.5 \mathrm{~cm}$. Treatment planning was computed tomographybased and dose prescribed was $85-100 \%$ isodose. Treatments has been delivered twice daily, six hours interval, and a review of reactions evaluated.

Results: Volume receiving more than $150 \%$ of the prescribed dose has been limited to less than $2 \%$, and that above $200 \%$ to be inside the mould. Brachytherapy equivalent dose at 2 Gy per fraction $\left(\mathrm{EQD}_{2}\right)$ of these patients was 24 and 28.6 Gy. Maximum dose to organ at risk (OAR) (2 cc of OAR) ranged between 55-87\% of prescribed dose, with a median dose being $80 \%$. All cases had only grade 1 post-radiotherapy skin immediate reactions, which resolved within four weeks. In all patients, no treatment failures were noted at nearly 2-years post-irradiation.

Conclusions: Surface mould brachytherapy in soft tissue sarcomas could be a useful alternative to interstitial brachytherapy, especially where the target volume is superficially extensive with underlying critical structures, and where catheter placement may be difficult, such as the shoulder.

Key words: brachytherapy, soft tissue sarcoma, surface mould.

\section{Purpose}

Soft tissue sarcomas (STSs) of the extremities are not commonly seen, and usually occurs in less than $1 \%$ of all adult tumors, but make up nearly half of all soft tissue sarcomas [1]. Many patients present with a progressively enlarging painless swelling $[1,2]$. Symptoms like local pain, neuralgias, or restriction of motor function can result later due to the involvement of nerve bundles, bone, or significant muscular compartment [2]. Radiotherapy and surgery have been the standard modalities in the treatment of extremity soft tissue sarcomas. Tumor grade is considered one of the main prognostic factors. Lowgrade tumors predominantly have the risk of local recurrence, requiring only adjuvant radiotherapy. On the other hand, most patients with intermediate or high-grade tu- mors larger than $5 \mathrm{~cm}$ in size, develop distant metastases compared to less than $10 \%$ in low-grade lesions or less than $5 \mathrm{~cm}$ in size $[3,4]$.

Adjuvant radiotherapy either used as interstitial brachytherapy or external beam radiotherapy (EBRT) has been found to improve local control rates (LC) in patients who have undergone limb-sparing resections with Level 1 evidence available $[5,6]$. For completely resected high-grade sarcomas of the extremities, brachytherapy can be used as the sole therapy if the target volume is localized and accessible, as it gives high doses to the tumor bed and extremely low doses to tissues outside the treated volume [7]. Data also suggests improved outcome with a combination of brachytherapy (interstitial) and EBRT for patients with positive margins $[8,9,10]$.
Address for correspondence: Ashutosh Mukherji, MD, Add. Prof., Department of Radiotherapy, Regional Cancer Centre, JIPMER, Puducherry-605006, India, phone: +91 9489146747,

$\bowtie$ e-mail: dr_ashutoshmukherji@yahoo.co.in
Received: 22.08 .2016

Accepted: 18.03 .2017

Published: 28.04.2017 


\section{Clinical and treatment details}

\section{Case history (Table 1)}

Case 1

A 48-year-old female patient was referred to the Radiotherapy Department for post-operative radiotherapy for a soft tissue sarcoma of the right shoulder. She presented with a history of a swelling developed over a sixmonth period (size and surgery details are not available),

Table 1. Patient characteristics

\begin{tabular}{lc} 
Total number of cases & Number \\
\hline Males & 1 \\
\hline Females & 2 \\
\hline Age group (years) & 1 \\
\hline $31-40$ & 2 \\
\hline $41-50$ & 0 \\
\hline$\geq 51$ & 0 \\
\hline Site involved & 1 \\
\hline Site involved & 2 \\
\hline Chest wall & 2 \\
\hline Shoulder & 1
\end{tabular}

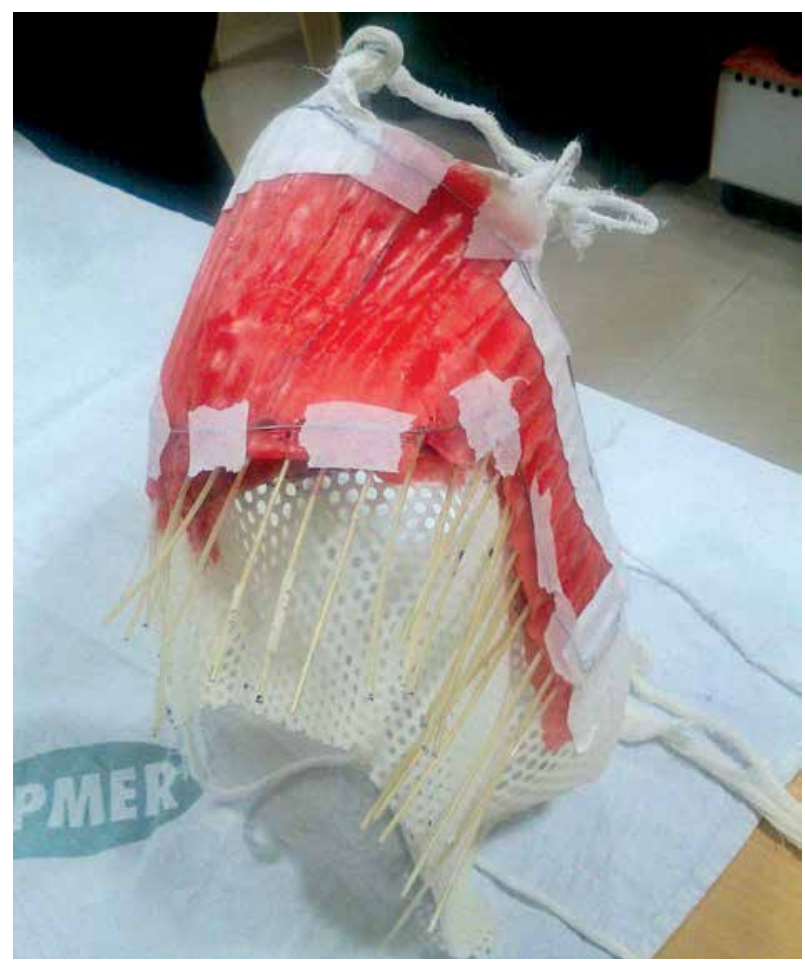

Fig. 1. Upper torso mould used in the first patient with extensive involvement of right shoulder tissue for which she subsequently underwent excision but no adjuvant therapy. A year later, the patient developed a $10 \mathrm{~cm} \times 6 \mathrm{~cm}$ recurrence, at the same site for which she presented to our Institute. A biopsy was done and it reported a low-grade fibrosarcoma, and metastatic workup was negative. The patient was advised surgery followed by adjuvant radiotherapy or surgery, and intra-operative interstitial brachytherapy as either single radiation modality or with external beam therapy. However, because of extensive horizontal spread of tumor and the proximity of humeral head with fears of graft rejection of postinterstitial brachytherapy, the patient was planned for surgery and post-operative radiotherapy. The patient then underwent wide local excision of the tumor and the histopathological review reported dermatofibrosarcoma with an involvement of the deep resected margin. Patient has been treated by external beam photon irradiation with $6 \mathrm{MV}$ photons, using AP-PA portals, with MLC blocking for lung shielding and use of bolus over surgical scar to a dose of $40 \mathrm{~Gy}$ in 20 fractions. After EBRT, a boost with surface mould brachytherapy using a base of thermoplastic immobilizer with wax mould was given (Figures 1 and 2). The patient received brachytherapy boost with dose of 3.5 Gy per fraction, twice daily, for seven fractions. Treatment was completed in February 2014.

\section{Case 2}

A 45-year-old female patient was referred to the Radiotherapy Department for post-operative radiotherapy for soft tissue sarcoma of left chest wall. She presented with a swelling over the left upper part of the chest in the infra-clavicular region developing over three years, and was operated at another hospital in January 2014 (size and surgery details are not available). A post-surgery histopathological review reported dermatofibrosarcoma protuberans with deep resected margin involved by tumor. The patient was subsequently treated by external beam photon irradiation with $6 \mathrm{MV}$ photons, using conventional AP-PA portals with lung shielding and use of bolus (of $0.5 \mathrm{~cm}$ thickness) over the surgical scar to a prescribed dose of 40 Gy in 20 fractions. This was followed by a boost, with surface mould brachytherapy to a dose of 3.5 Gy per fraction, twice daily for 7 fractions (Figure 3). The patient completed treatment in April 2014.

\section{Case 3}

A 36-year-old male patient has been referred to the Radiotherapy Department for post-operative radiotherapy of soft tissue sarcoma of the anterior shoulder at left side. He had presented in another hospital with a swelling of the left anterior shoulder over ten months. Local examination reported an $8 \times 6 \mathrm{~cm}$ mass lesion with no nodes or restriction of mobility. The patient underwent surgery. The post-surgery histopathological review reported the mass as a low-grade sarcoma with fibro sarcomatous pattern and with involved deep margin. The patient then received external beam radiotherapy with $6 \mathrm{MV}$, using APPA portals with the use of bolus of $0.5 \mathrm{~cm}$ over surgical scar to a dose of 44 Gy in 22 fractions, followed by a boost with surface mould brachytherapy to a dose of 3.5 Gy per 

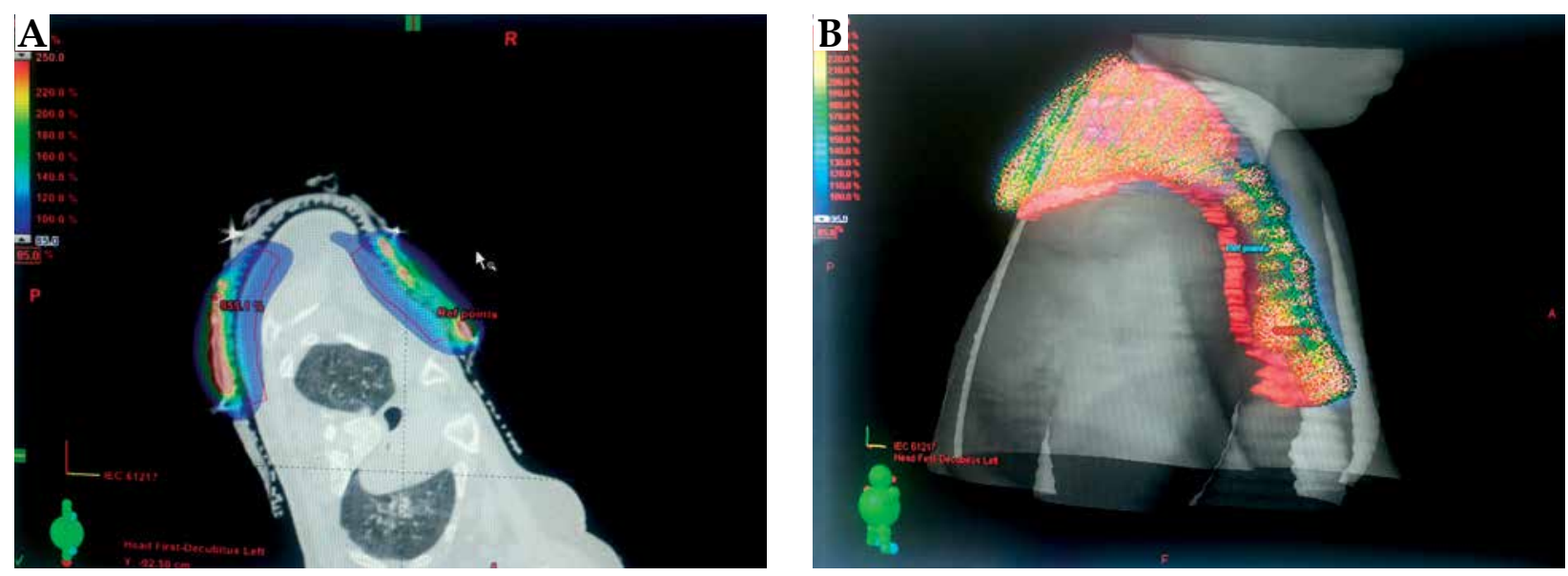

Fig. 2. A) Site of mould in the first patient. B) Computed tomography image with mould in place in the first patient

fraction twice daily for six fractions. The patient completed treatment in June 2014.

\section{Mould preparation}

Each mould was prepared from a framework of thermoplastic sheet molded to the patient's anatomy, and then covered by thin layer of dental wax. After marking of target volume by the oncologist, the physicist helped to make an initial cut-out with thermoplastic sheet. Then the wax was heated in a water heater, and cast in the required shape over the thermoplastic and molded according to local anatomy. The shaped wax mould was approximated to the lesion in the treatment position, matched with lesion surface and local anatomy, edges were trimmed and smoothened. Catheters were fixed to the mould, which was then placed on the patient to check the feasibility of placement and target volume coverage (Figure 1). The lesion was then marked with lead wires and computed tomography (CT)-simulation of the patient in the treatment position was done with mould in place.

\section{Treatment planning and delivery}

After CT-simulation, image reconstruction, target volume contouring, and treatment planning was carried out on Eclipse (Varian Medical Systems, Palo Alto, CA, USA) TPS version 10.0, and treatment delivery was done on GammaMedplusiX (Varian Medical Systems, Palo Alto, CA, USA). The target volume was defined as the volume encompassing the tumor bed with lateral margins of $2-2.5 \mathrm{~cm}$ and depth of $1-1.5 \mathrm{~cm}$. The tumor bed has been identified by comparing pre-operative and post-operative CT/magnetic resonance (MR) films, as well as taking into account the surgical scar. Dosimetry has been done using volume optimization techniques. The dose was prescribed to $80 \%, 85 \%$, and $90 \%$ isodose lines, respectively, in the three cases in order to cover the depth of 1-1.5 cm (Figures 2, 3 and 4). Treatments were delivered twice daily, six hours interval, and review of reactions was done every third day and at the completion. Evaluation was done of planning details, response to therapy, and reactions encountered.

\section{Observations}

All patients tolerated the mould boost well with skin darkening as observed towards the end of treatment, and grade 2 skin changes seen in the second and third patients. Grade 1 skin changes were seen in all three cases (Figure 5). Brachytherapy dose ranged from 21-24.5 Gy in frac-
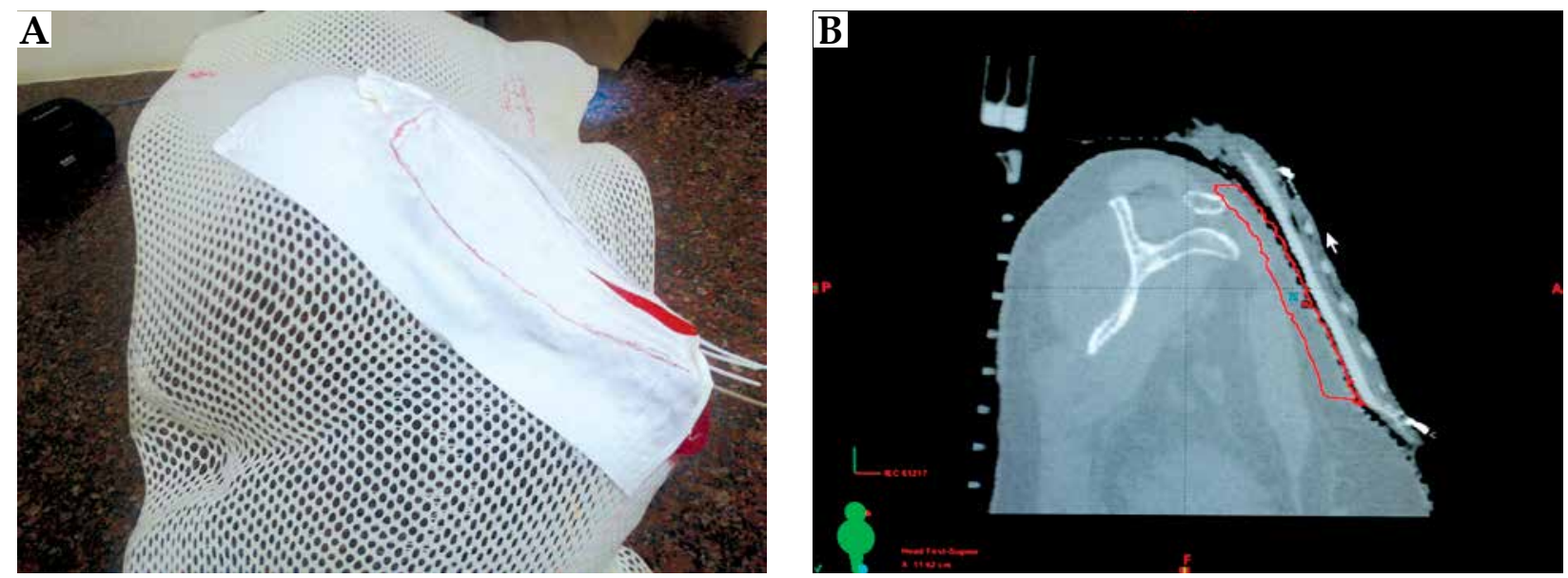

Fig. 3. A) Site of mould in second patient. B) Computed tomography image with mould in place in second patient 

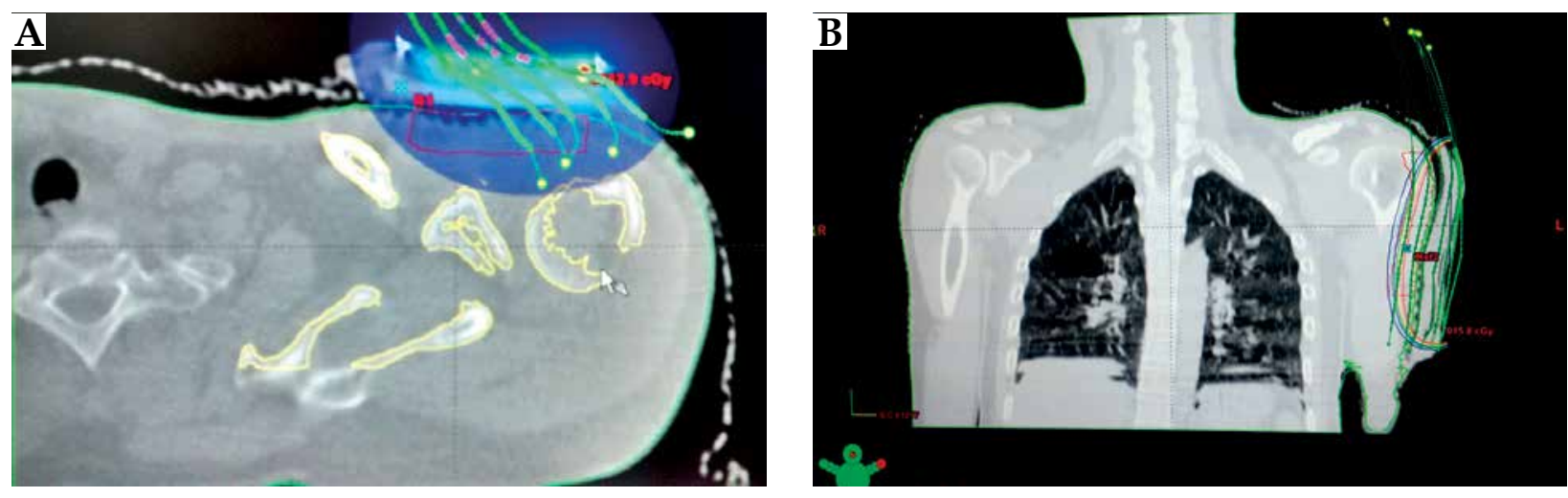

Fig. 4. A) Dose color wash in the second patient. B) Isodose distribution with overlying catheters in the third patient

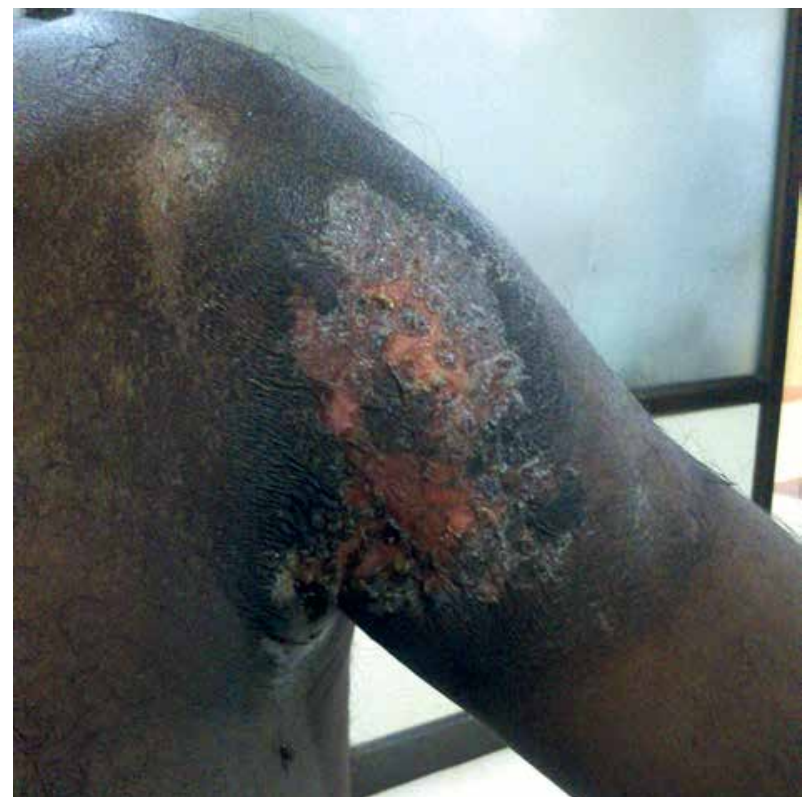

Fig. 5. Immediate post-radiotherapy skin changes in the third patient

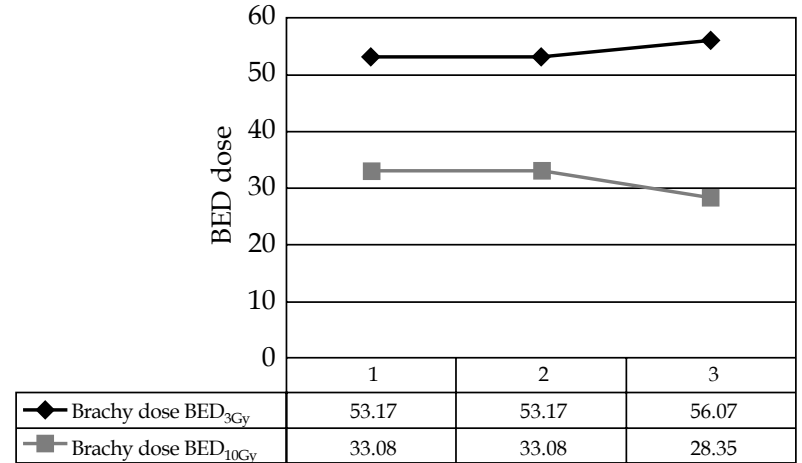

Fig. 6. Biologically equivalent dose (BED) of treated cases

tion sizes of 3.5 Gy, delivered twice daily. Brachytherapy part EQD 2 of these patients were 24 and $28.6 \mathrm{~Gy}$, while total EQD $\mathrm{ED}_{2}$ of these patients was $68.5 \mathrm{~Gy}$ in the three cases. Biologically equivalent dose for 3 and $10 \mathrm{~Gy}$ has been also calculated (Table 2 and Figure 6) in all cases, and the total $\mathrm{BED}_{3}$ dose (including external beam component) has been between 119-129 Gy in all cases. Selecting an isodose of $85-100 \%$ (Figure 7) helped in achieving maximal

Table 2. Dose characteristics

\begin{tabular}{|c|c|c|c|c|c|c|c|c|}
\hline \multirow[t]{2}{*}{ Age/sex } & \multicolumn{2}{|c|}{ Brachytherapy dose } & \multicolumn{2}{|c|}{ EBRT dose } & \multirow{2}{*}{$\begin{array}{c}\text { No. of } \\
\text { channels }\end{array}$} & \multirow[t]{2}{*}{$\mathrm{EQD}_{2} \mathrm{cGy}$} & \multicolumn{2}{|c|}{ Brachytherapy dose } \\
\hline & $\begin{array}{c}\text { Total dose } \\
\text { (\# dose) }\end{array}$ & Fractions & Total dose & Fractions & & & $\mathrm{BED}_{3 \mathrm{~Gy}}$ & $\mathrm{BED}_{10 \mathrm{~Gy}}$ \\
\hline $48 / F$ & $24.5(3.5)$ & 7 & 40 Gy & 20 & 28 & $40+28.58=68.58$ & 53.17 & 33.08 \\
\hline $45 / F$ & $24.5(3.5)$ & 7 & 40 Gy & 20 & 4 & $40+28.58=68.58$ & 53.17 & 33.08 \\
\hline $36 / M$ & $21.0(3.5)$ & 6 & 44 Gy & 22 & 8 & $44+24.50=68.50$ & 56.07 & 28.35 \\
\hline
\end{tabular}

$E Q D_{2}$ - equivalent dose at 2 Gy per fraction, $B E D_{3 G y} / B E D_{10 G y}$ - biologically equivalent dose for late effects $\left(B E D_{3 G y}\right)$ and for early effects (BED $\left.10 G y\right), \#-$ fraction, $E B R T$ - external beam radiation therapy

Table 3. Dose volume comparisons

\begin{tabular}{lccccccc}
$\begin{array}{l}\text { Case } \\
\text { number }\end{array}$ & Age/sex & $\begin{array}{c}\text { Prescription } \\
\text { isodose to PTV }\end{array}$ & $\mathrm{V}_{200 \%}$ & $\mathrm{~V}_{150 \%}$ & $\begin{array}{c}\text { Depth of PTV } \\
\text { coverage }\end{array}$ & $\begin{array}{c}\text { Lateral margins } \\
\text { for PTV }\end{array}$ & $\begin{array}{c}\text { \% PTV covered by } \\
\text { prescription isodose }\end{array}$ \\
\hline 1 & $48 / \mathrm{F}$ & $80 \%$ & $0.001 \%$ & $1.0 \%$ & 1.1 & $2.0 \mathrm{~cm}$ & 100 \\
\hline 2 & $45 / \mathrm{F}$ & $85 \%$ & $0.001 \%$ & $0.5 \%$ & 1.2 & $2.5 \mathrm{~cm}$ & 80 \\
\hline 3 & $36 / \mathrm{M}$ & $90 \%$ & $0.001 \%$ & $0.6 \%$ & 1.6 & $2.0 \mathrm{~cm}$ & 70
\end{tabular}

PTV - planning target volume, $V_{200 \%}$ - volume receiving $200 \%$ of prescribed dose, $V_{150 \%}$-volume receiving $150 \%$ of prescribed dose 


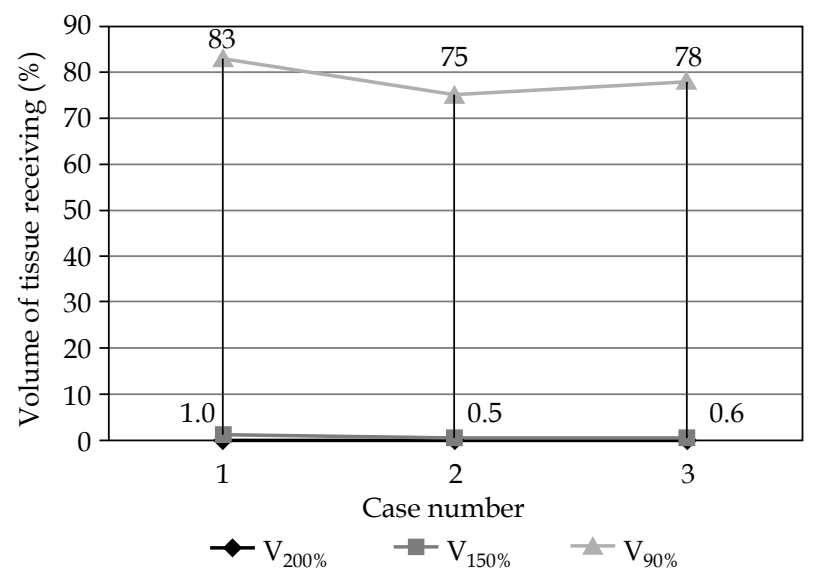

Fig. 7. Tissue volume and dose received

tumor volume coverage, while at the same time, keeping volume of tissue receiving more than $150 \%\left(\mathrm{~V}_{150}\right)$ to below $2 \%$ and volume of tissue receiving more than $200 \%\left(\mathrm{~V}_{200}\right)$ of prescribed dose to below $0.001 \%$. This meant that areas receiving more than $200 \%$ of the prescribed dose were limited to the substance of the mould (Table 3 and Figure 7). The underlying bone in all cases was the organ at risk (OAR). Maximum dose to OAR was assessed as dose to 2 cc of OAR and ranged between $55-87 \%$ of the prescribed dose with a median dose being $80 \%$ (Figure 8 ).

\section{Sequelae and survival}

There were no severe skin reactions like ulcers or necrosis (Table 4). At six months of follow-up, none of the patients showed any local or distal recurrence both clinically as well by imaging (CT thorax and local MRI). All the cases again reported for follow-up in March 2015, in August 2015, in January 2016, July 2016, October 2016, and January 2017 (Figures 9 and 10). By then, patients had completed 36, 34, and 32 months uneventful follow-up, respectively. Local examination and imaging showed no local recurrence or distant metastases or even no local site late treatment sequelae (Figure 11, Table 4).

\section{Discussion}

Post-operative or adjuvant radiotherapy in soft tissue sarcomas are indicated in situations with increased risk of local recurrence after surgery. These include cases with narrow or positive surgical margins, local recurrence after prior surgery, tumor size of more than $5 \mathrm{~cm}$, as well as lesions deep to or invading the superficial fascia, high grade, or age of patient younger than 50 years [3].

Interstitial brachytherapy has been more commonly used and can achieve good dose distribution especially in limited target volumes, and helps to achieve good control rates $[11,12]$. Early results from Memorial Sloan-Kettering Cancer Center (MSKCC) have shown better results when the brachytherapy is added to radiotherapy as adjuvant therapy, especially in cases with positive margins [8] as well as in recurrent disease $[9,13]$. In France, the Gustav Roussy Institute reported 80\% local control rates with interstitial brachytherapy, but $30 \%$ margin failures

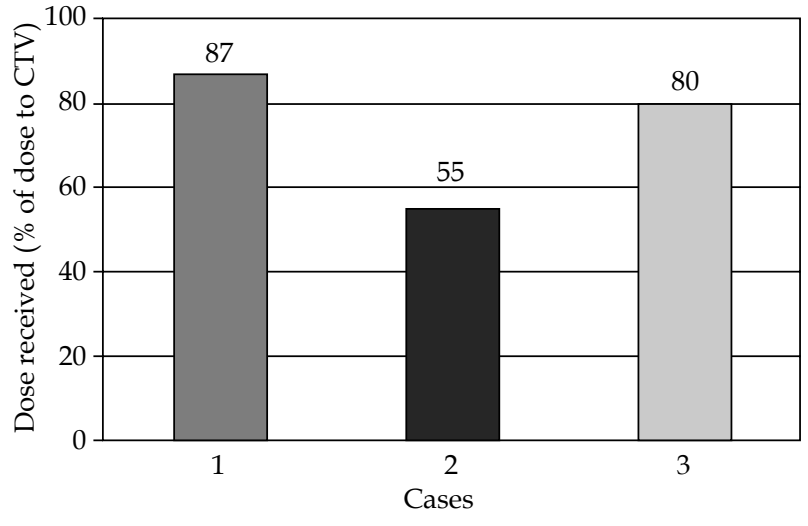

Fig. 8. Dose to organ at risk (head of humerus)

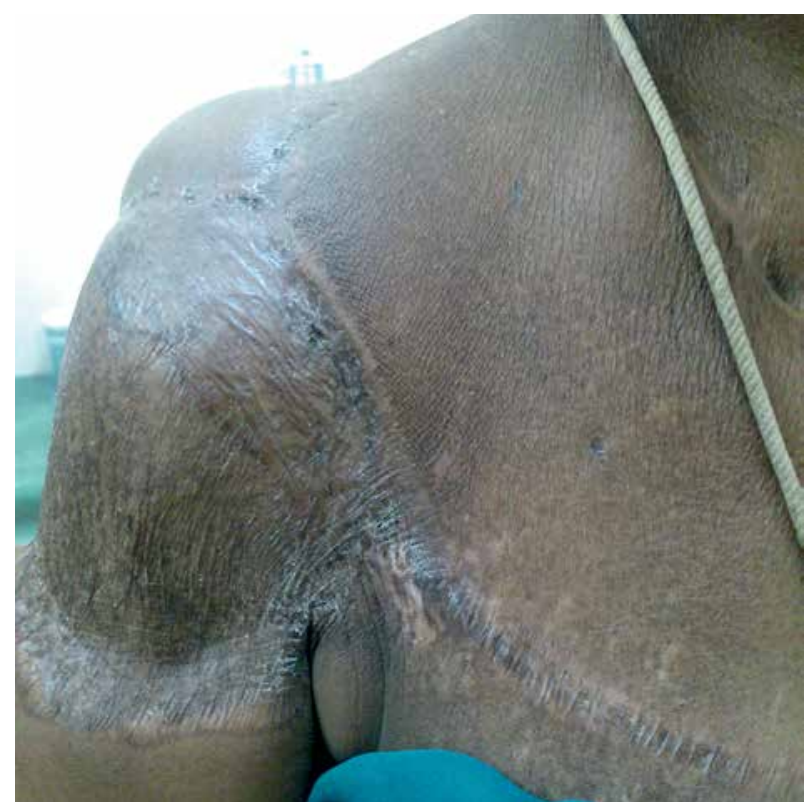

Fig. 9. Skin changes in the first patient, photograph taken 3 months post-radiotherapy

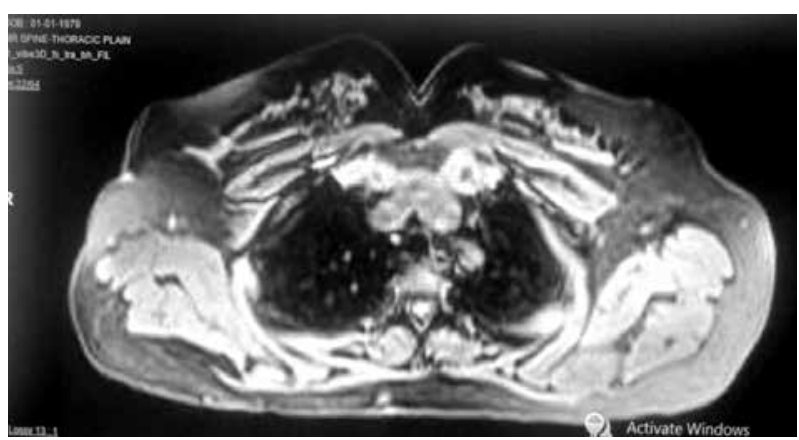

Fig. 10. Magnetic resonance imaging in the third patient, photograph taken at 27 months post-radiotherapy showing no local recurrence

and a $35 \%$ necrosis rate [14]. However, the use of interstitial brachytherapy in the treatment of sarcomas is associated with certain constraints. These include difficulty in covering a larger target volume, limits in catheter patterns, achieving good geometry because of the presence of bone or visceral organs or difficult anatomic sites 
Table 4. Skin reactions and survival

\begin{tabular}{|c|c|c|c|c|c|c|c|c|c|c|}
\hline \multirow[t]{2}{*}{$\begin{array}{l}\text { Case } \\
\text { number }\end{array}$} & \multicolumn{4}{|c|}{$\begin{array}{c}\text { Skin reactions grade at } 4 \text { weeks } \\
\text { post-brachytherapy (acute reactions) }\end{array}$} & \multicolumn{4}{|c|}{$\begin{array}{c}\text { Skin reactions/scar/fibrosis at } 30 \text { months } \\
\text { post-brachytherapy (late effects) }\end{array}$} & \multirow{2}{*}{$\begin{array}{c}\text { Follow-up } \\
\text { period } \\
\text { (in months) }\end{array}$} & \multirow{2}{*}{$\begin{array}{c}\text { Disease free } \\
\text { survival } \\
\text { (in months) }\end{array}$} \\
\hline & Grade 1 & Grade 2 & Grade 3 & Grade 4 & Grade 1 & Grade 2 & Grade 3 & Grade 4 & & \\
\hline 1 & Yes & No & No & No & No & No & No & No & 36 & 36 \\
\hline 2 & Yes & Yes & No & No & No & No & No & No & 34 & 34 \\
\hline 3 & Yes & Yes & No & No & No & No & No & No & 32 & 32 \\
\hline
\end{tabular}

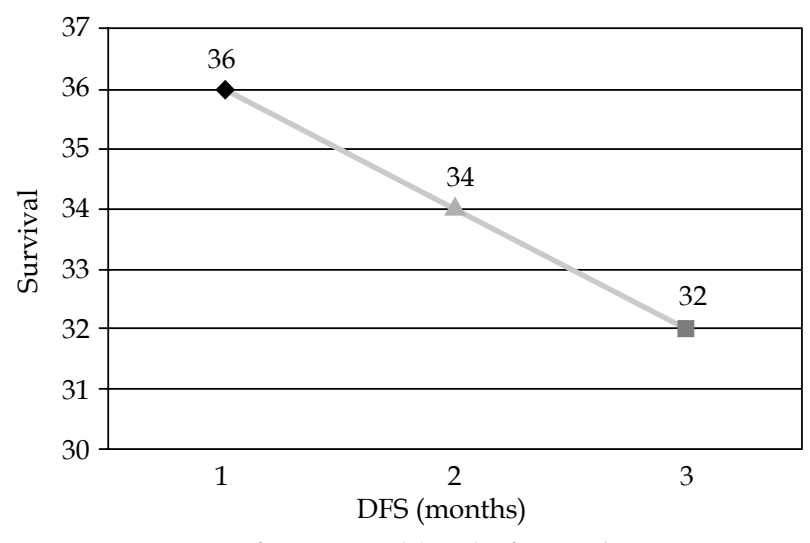

Fig. 11. Disease free survival (DFS) of treated cases

such as around the shoulder, and risk of radiation injury to nerves that are in direct contact with the BT catheters. The MSKCC group noticed that shoulder location was an independent prognostic factor for poor local control with interstitial brachytherapy [7]. Therefore, in many of these situations, particularly when the target volume is superficially located, a customized mould using acrylic or thermoplastic casts can be used for catheter placement, geometry, and even the immobilization. The brachytherapy catheters are laid directly onto the mould or can be used with a spacer such as in Freiburg flap to ensure uniform catheter distribution.

Compared to interstitial brachytherapy, surface mould brachytherapy though extensively studied in skin cancers, head and neck, scalp, or even intra-ocular regions, has not been widely used for treating extremity soft tissue sarcomas, and dose guidelines have to be extrapolated from interstitial brachytherapy. These custom-made external molds can result in dose distribution with a sharp gradient in the edges of the applicator, especially over curved or irregular surfaces, and are easy to use with highly accurate daily treatment reproduction. They enable one to obtain excellent local control with minimum treatment-related sequelae or late complications. In our case series, the position of the tumor bed in all the three cases was very close to the head of humerus and with deep involved margins, and the need was not only to adequate cover the area at risk, but also to achieve sharp dose fall-off to avoid the joint or bone. It is better to prescribe to isodose of $85-100 \%$ to obtain an acceptable coverage of the target volume to limit the amount of tissue irradiated by $150 \%$ isodose. Any attempt to pull the isodose outward to cover a bigger target volume altogether could result in more tissue receiving doses above
$200 \%$ and cause severe skin reactions. In all our cases, the authors managed to keep the area receiving dose of $200 \%$ and above to within the substance of the mould, while area receiving above $150 \%$ is less than $2 \%$. Thus, the use of surface moulds can result in dose distributions more homogeneous than even electron beam therapy [15], and may even rival IMRT with the added benefits of minimal surrounding tissue dose and much less integral body dose [16]. In our series, we noticed grade 1 skin changes in all cases and grade 2 reactions in 2 cases. Furthermore, all reactions healed within six weeks.

\section{Conclusions and learning points}

Treatment of soft tissue sarcomas of the extremities requires usually combined modality therapy. Brachytherapy, usually interstitial, plays an useful role in the treatment of soft tissue sarcomas of the extremities helping achieve improved local control with both organ and function preservation.

Surface mould brachytherapy can be a valuable alternative to interstitial brachytherapy, especially in cases where the target volume is extensively superficial, underlying critical structures, and where catheter placement may be difficult, such as the shoulder, with excellent medium term local control and mild toxicity.

\section{Disclosure}

Authors report no conflict of interest.

\section{References}

1. Brennan MF, Shiu MH, Collin C et al. Extremity soft tissue sarcomas. Cancer Treat Symp 1985; 3: 71-81.

2. Hunt K, Vorburger S, Cormier J. Surgical approaches to extremity sarcoma. In: Soft tissue sarcomas. Pollock R (ed.). B.C. Decker, London 2002; 89-109.

3. Coindre JM, Terrier P, Bui NB et al. Prognostic factors in adult patients with locally controlled soft tissue sarcoma. A study of 546 patients from the French Federation of Cancer Centers Sarcoma Group. J Clin Oncol 1996; 14: 869-877.

4. Suit HD, Mankin HJ, Wood WC et al. Preoperative, intraoperative and postoperative radiation in the treatment of primary soft tissue sarcoma. Cancer 1985; 55: 2659-2667.

5. Yang JC, Chang AE, Baker AR et al. Randomized prospective study of the benefit of adjuvant radiation therapy in the treatment of soft tissue sarcomas of the extremity. J Clin Oncol 1998; 16: 197-203.

6. Brennan MF, Hilaris B, Shiu MH et al. Local recurrence in adult soft-tissue sarcoma. A randomized trial of brachytherapy. Arch Surg 1987; 122: 1289-1293. 
7. Alektiar KM, Leung D, Zelefsky MJ et al. Adjuvant brachytherapy for primary high-grade soft tissue sarcoma of the extremity. Ann Surg Oncol 2002; 9: 48-56.

8. Alekhteyar KM, Leung DH, Brennan MF et al. The effect of combined external beam radiotherapy and brachytherapy on local control and wound complications in patients with high-grade soft tissue sarcomas of the extremity with positive microscopic margin. Int J Radiat Oncol Biol Phys 1996; 36: 321-324.

9. Petera J, Soumarová R, Ruzicková J et al. Perioperative hyperfractionated high-dose rate brachytherapy for the treatment of soft tissue sarcomas: Multicentric experience. Ann Surg Oncol 2010; 17: 206-210.

10. Cahlon O, Brennan MF, Jia X et al. A postoperative nomogram for local recurrence risk in extremity soft tissue sarcomas after limb-sparing surgery without adjuvant radiation. Ann Surg 2012; 255: 343-347.

11. Guix B, Finestres F, Tello JI et al. Treatment of skin carcinomas of the face by high dose rate brachytherapy and custom made surface molds. Int J Radiat Oncol Biol Phys 2000; 47: 95-102.

12. Evans MD, Yassa M, Podgorsak EB et al. Surface applicators for high dose rate brachytherapy in AIDS-related Kaposi's sarcoma. Int J Radiat Oncol Biol Phys 1997; 39: 769-774.

13. Chun M, Kang S, Kim BS et al. High dose rate interstitial brachytherapy in soft tissue sarcoma: Technical aspects and results. Jpn J Clin Oncol 2001; 31: 279-283.

14. Habrand JL, Gerbaulet A, Pejovic MH et al. Twenty years' experience of interstitial iridium brachytherapy in the management of soft tissue sarcomas. Int J Radiat Oncol Biol Phys 1991; 20: 405-411.

15. Stewart AJ, O'Farrell DA, Bellon JR et al. CT computer optimized high dose rate brachytherapy with surface applicator technique for scar boost radiation following breast reconstruction surgery. Brachytherapy 2005; 4: 224-229.

16. Alektiar KM, Brennan MF, Singer S. Local control comparison of adjuvant brachytherapy to intensity-modulated radiotherapy in primary high-grade sarcoma of the extremity. Cancer 2011; 117: 3229-3234. 


\section{reklama}

Brachy Academy

General 